\title{
Trends in organised sport membership: Impact on sustainability
}

\author{
Rochelle Eime*, Warren Payne, Jack Harvey
}

School of Human Movement and Sport Sciences, University of Ballarat, Australia

\section{Introduction}

Sport plays a very strong social and cultural role across many countries. ${ }^{1}$ In Australia, New Zealand, Britain and some European countries, the

* Corresponding author.

E-mail address: r.eime@ballarat.edu.au (R. Eime). traditional and principal means of sports participation is via membership of a single or multi-sport focused community sporting club. ${ }^{1,2}$ Such participation plays an important role in meeting an individual's leisure needs and in increasing community-wide levels of physical activity. ${ }^{1,3}$ In addition to the physical health benefits, participation in community-level sport is associated 
with a range of mental health benefits and contributes to community wellbeing and social capital. 4,5 Given these benefits, the promotion of participation in community level sport has been advocated in a number of governmental public health initiatives. ${ }^{6,7}$

Community sporting clubs provide an opportunity for both structured (organised and competitive) and unstructured (social) participation. Given the strong relationship between community sport participation and both individual and community wellbeing, it is important to monitor the level of community engagement in sporting activities. It is also important to acknowledge that the structure of sporting clubs is dependent upon volunteer involvement. ${ }^{8}$

A number of approaches; including national surveys; have been used to monitor the incidence of community sport engagement as a way of assessing the efficacy of the various public health initiatives that have focused upon sport. However, these data can often be contradictory. For example, data collected in the Australian Exercise, Recreation and Sport Survey (ERASS), show a rise in the proportion of adults who participate in these activities from 2001 to 2004. In contrast, data collected by the Australian Bureau of Statistics (ABS) showed a slight decrease in participation rates in all sport and physical activities from 1998-1999 to 1999-2000 before a rise in 2002. ${ }^{9-11}$ With regard to organised physical activity by adults, both ERASS and ABS reported rises from 2001 to $2004 .{ }^{11-13}$

It is possible that broad, national level surveys do not adequately define sport participation. For example, both the ERASS and ABS surveys only report information on persons aged $15+$ years. Secondly, they both define sport participation more broadly than either club membership or active participation to an extent sufficient to incur a health benefit.

In the light of these limitations and given the acknowledged key role of sporting clubs and club membership in the promotion of community-level physical activity and health, the aim of this study was to explore in detail the patterns of club membership in a range of sporting associations in the Australian state of Victoria.

\section{Methods}

The data were collected as part of the evaluation of the Partnerships for Health Scheme (PfHS) conducted by the Victorian Health Promotion Foundation (VicHealth). The PfHS implements capacity building strategies including creating healthy and welcoming club environments, together with various participation programs, as a means to increase the participation by Victorians in both structured and unstructured sport. The ultimate goal of the $\mathrm{PfHS}$ is an increase in club membership. VicHealth invests over $\mathrm{A} \$ 3$ million annually in the PfHS. ${ }^{14}$ The $\mathrm{PfHS}$ is delivered through partnerships established with Victorian State Sporting Associations (SSAs) (50 in 2004 and 49 in 2005), which are the sport governing bodies within the state of Victoria. The funded SSAs have over 9500 affiliated clubs which service the needs of most of Victoria's sports participants.

Sport was defined as per the Council of Europe definition: "Sport" means all forms of physical activity which, through casual or organised participation, aim at expressing or improving physical fitness and mental well-being, forming social relationships or obtaining results in competition at all levels. ${ }^{15}$

Two methodologies were adopted. Each of the 50 SSAs funded by VicHealth in 2004 were requested to provide their full membership databases for the previous 10 years. The SSAs were informed that these data would be categorised according to the objectives of the PfHS, and that their sport would not be identified in the published results. All sports that provided complete membership data for the 6 years from 1998 to 2003 inclusive were included and trends in membership analysed. As well as total membership, membership counts were broken down into three mutually exclusive and exhaustive categories: adults (18+ years); juniors (8-17 years); and participants in modified sports (5-7 years). The numbers in each age category were expressed as percentages of the total membership. For each sport, trends in the counts for each membership category were examined by calculating the change in the count over the period 1998-2003 and expressing it as a percentage of the 1998 figure. The average annual rate of change (AAR) was calculated as the geometric mean of the annual rates of change. The trend in the proportion in each membership category was examined by calculating the change in the proportion over the period 1998-2003. The average annual change (AAC) in each proportion was calculated as the arithmetic mean of the annual changes. For each membership category, mean values of the AAR and AAC were calculated, together with $95 \%$ confidence intervals. It should be noted that whilst the assumption of normal errors was not violated for any of the reported analyses, the applicability of the Cls is limited by the fact that the inclusion criteria (see Results and Discussion below) resulted in a small sample of 
relatively large organisations whose membership profiles may or may not be representative, either of the immediate population of 50 SSAs or of the broader population of sporting organisations in general.

A web-based survey was also administered in 2005 to each of the 49 VicHealth-funded SSAs. This survey collected information on factors affecting the involvement of 'active' and 'involved' registered members of each SSA. An 'active' participant is defined as a player or official who is physically active. An 'involved' participant is one who is engaged in a non-physical manner, e.g. coach, official. ${ }^{17}$ The survey was approved by the University Human Research Ethics Committee.

\section{Results}

Slightly more than half $(56.8 \%)$ of the 50 SSAs contacted in 2004 provided membership data. Data from only four sports were complete and spanned at least 6 years. Membership data were analysed for the 6 years from 1998 to 2003 for these four sports (Table 1). Three sports reported increases in total membership whilst one sport reported a decrease; the mean AAR was $+3.4 \% ; 95 \% \mathrm{Cl}(-6.3 \%$, $+13.1 \%$ ).

There were marked decreases in both the absolute number and the proportion of members who were adults $(18+$ years). Three of the sports reported a decrease in the absolute number of adult members over the 6-year period and one reported an increase; the mean AAR was $-0.9 \%$; $95 \%$ $\mathrm{Cl}(-5.7 \%,+3.9 \%)$. The proportion of adult members decreased in all four sports across the 6-year period; the mean AAC was $-1.3 \% ; 95 \% \mathrm{Cl}(-2.7 \%$, $+0.1 \%)$. Across the four sports, the proportion of the total membership within the adult category in 2003 varied from $16 \%$ to $56 \%$.

The proportion of non-adult members increased in all four sports across the 6-year period. However, interpretation of trends in junior participation rates is complicated by the existence of modified junior versions of the sports. Modified versions were reported throughout the study period in two cases, and were introducted during the study period in the other two cases. The number of participants registered as junior club members increased slightly over the 6-year period in two sports increased substantially in one sport and decreased in the fourth sport; the mean AAR was $+1.7 \%$; $95 \% \mathrm{Cl}$ $(-10.8 \%,+14.1 \%)$. The substantial decrease in junior members in Sport 1 was the result of a separate modified category in 2001, resulting in a transfer of approximately 20,000 junior participants (over $30 \%$ of junior members). After 2000 , the number of junior members then increased by an average of $2.6 \%$ per year. Across all sports, the proportion of the total membership within the junior category in 2003 varied from 23\% to $63 \%$.

Membership in the modified sport category increased markedly for one sport and slightly for two sports. In one sport, a decrease occurred which was substantial in percentage terms although the numbers registered in the modified form of this sport were small. The mean AAR was $+10.7 \%$; $95 \%$ $\mathrm{Cl}(-36.5 \%,+58.0 \%)$. The mean AAC in the proportion of total membership in the modified forms was $+0.8 \% ; 95 \% \mathrm{Cl}(-0.9 \%,+2.6 \%)$. These changes resulted in the proportion of the total membership participating in this category either staying the same or increasing by $2-3 \%$ points over the reporting period. Across the four sports, the proportion of the total membership within the modified sport category in 2003 varied from close to $0 \%$ up to $60 \%$.

The response rate for the web-based survey overall was $91.8 \%$ of 49 funded SSAs. However, responses varied according to each question and the nature of some questions meant that they were not applicable to all SSAs. For example, a question regarding perceived reasons for the changes in membership numbers was answered by 19 SSAs. The most common response regarding the increase in total number of members who actively participated in the sport was new programs or competitions being offered $(n=7,36.8 \%$ of responding SSAs). Three SSAs (15.8\% of responding SSAs) reported that an increased number of qualified coaches was also a facilitator to membership growth. Seven SSAs provided reasons for decreases in membership; the only response offered by more than one SSA was the death of members in sports with high levels of participation by older persons.

\section{Discussion}

Before examining the implications of these results, it is appropriate to acknowledge the limitations of the membership data analysed in this study. Reasons for the poor response rate of SSAs to the request to provide membership databases and the limited scope of much of the data provided is beyond the scope of this paper. Nevertheless, the four sports for which longitudinal data were 


\begin{tabular}{|c|c|c|c|c|c|c|c|c|c|}
\hline Category & Sport & 1998 & 1999 & 2000 & 2001 & 2002 & 2003 & $\begin{array}{l}\text { Rate of change } \\
1998-2003(\%)\end{array}$ & $\begin{array}{l}\text { Average annual rate of } \\
\text { change (AAR) (\%) }\end{array}$ \\
\hline \multicolumn{10}{|c|}{ Membership numbers } \\
\hline \multirow[t]{4}{*}{ Adult } & 1 & 50,894 & 49,338 & 42,025 & 41,645 & 42,081 & 42,498 & -16.5 & -3.5 \\
\hline & 2 & 32,465 & 31,929 & 31,540 & 31,306 & 31,476 & 30,751 & -5.3 & -1.1 \\
\hline & 3 & 57,919 & 57,494 & 57,614 & 56,576 & 56,186 & 51,599 & -10.9 & -2.3 \\
\hline & 4 & 5,535 & 6,377 & 7,536 & 7,510 & 7,415 & 6,544 & 18.2 & 3.4 \\
\hline \multirow[t]{4}{*}{ Junior } & 1 & 57,553 & 58,702 & 37,791 & 38,160 & 40,028 & 40,788 & -29.1 & -6.7 \\
\hline & 2 & 42,788 & 42,731 & 43,888 & 43,449 & 43,556 & 43,947 & 2.7 & 0.5 \\
\hline & 3 & 39,851 & 40,351 & 39,971 & 39,364 & 41,139 & 41,221 & 3.4 & 0.7 \\
\hline & 4 & 10,532 & 12,144 & 12,780 & 13,618 & 14,219 & 18,730 & 77.8 & 12.2 \\
\hline \multirow[t]{4}{*}{ Modified } & 1 & & & 24,848 & 24,784 & 25,717 & 26,961 & $8.5^{\mathrm{a}}$ & $2.8^{\mathrm{a}}$ \\
\hline & 2 & 96,786 & 102,735 & 102,753 & 102,513 & 108,276 & 114,063 & 17.9 & 3.3 \\
\hline & 3 & & & 460 & 180 & 170 & 270 & $-41.3^{a}$ & $-16.3^{\mathrm{a}}$ \\
\hline & 4 & 535 & 1,800 & 1,744 & 2,400 & 3,500 & 4,500 & 741.1 & 53.1 \\
\hline \multirow[t]{4}{*}{ Total } & 1 & 108,447 & 108,040 & 104,664 & 104,589 & 107,826 & 110,247 & 1.7 & 0.3 \\
\hline & 2 & 172,048 & 177,381 & 178,191 & 177,269 & 183,318 & 188,775 & 9.7 & 1.9 \\
\hline & 3 & 97,770 & 97,845 & 97,585 & 95,940 & 97,325 & 92,820 & -5.1 & -1.0 \\
\hline & 4 & 16,602 & 20,321 & 22,061 & 23,528 & 25,135 & 29,773 & 79.3 & 12.4 \\
\hline Category & Sport & $1998(\%)$ & 1999 (\%) & $2000(\%)$ & $2001(\%)$ & $2002(\%)$ & $2003(\%)$ & $\begin{array}{l}\text { Change in percentage } \\
1998-2003(\%)\end{array}$ & $\begin{array}{l}\text { Average annual change } \\
\text { in Percentage (AAC) }(\%)\end{array}$ \\
\hline \multicolumn{10}{|c|}{ Membership proportions } \\
\hline \multirow[t]{4}{*}{ Adult } & 1 & 46.9 & 45.7 & 40.2 & 39.8 & 39.0 & 38.5 & -8.4 & -1.7 \\
\hline & 2 & 18.9 & 18.0 & 17.7 & 17.7 & 17.2 & 16.3 & -2.6 & -0.5 \\
\hline & 3 & 59.2 & 58.8 & 59.0 & 59.0 & 57.7 & 55.6 & -3.6 & -0.7 \\
\hline & 4 & 33.3 & 31.4 & 34.2 & 31.9 & 29.5 & 22.0 & -11.4 & -2.3 \\
\hline \multirow[t]{4}{*}{ Junior } & 1 & 53.1 & 54.3 & 36.1 & 36.5 & 37.1 & 37.0 & -16.1 & -3.2 \\
\hline & 2 & 24.9 & 24.1 & 24.6 & 24.5 & 23.8 & 23.3 & -1.6 & -0.3 \\
\hline & 3 & 40.8 & 41.2 & 41.0 & 41.0 & 42.3 & 44.4 & 3.6 & 0.7 \\
\hline & 4 & 63.4 & 59.8 & 57.9 & 57.9 & 56.6 & 62.9 & -0.5 & -0.1 \\
\hline \multirow[t]{4}{*}{ Modified } & 1 & & & 23.7 & 23.7 & 23.9 & 24.5 & $0.7^{\mathrm{a}}$ & $0.2^{\mathrm{a}}$ \\
\hline & 2 & 56.3 & 57.9 & 57.7 & 57.8 & 59.1 & 60.4 & 4.2 & 0.8 \\
\hline & 3 & & & 0.5 & 0.2 & 0.2 & 0.3 & $-0.2^{\mathrm{a}}$ & $-0.1^{\mathrm{a}}$ \\
\hline & 4 & 3.2 & 8.9 & 7.9 & 10.2 & 13.9 & 15.1 & 11.9 & 2.4 \\
\hline
\end{tabular}


reported represent four of the most popular organised activities in Victoria in 2004. ${ }^{11}$ Consequently, we are confident that these data are at least indicative of club membership trends in major sports within Victoria, but we acknowledge it is possible that changes in the membership of these particular sports do not reflect changes in the membership for all sports within Victoria. Further, we acknowledge that there is only a partial alignment between the group of SSAs who provided data regarding changes in membership and the larger group of SSAs who reported reasons for changes in membership.

These data present a different perspective on sports participation to the data reported in population surveys. ${ }^{8-13}$ Firstly, this study focuses specifically upon sporting association membership to the exclusion of participation in other forms of organised activity such as those offered by leisure centres, or other forms of occasional sport participation such as 'pay and play'. Secondly, this study is broader in scope as it includes members of sporting clubs aged $<15$ years and also includes children who participate in modified sport. Therefore, it has been possible to report membership levels for each of the three major membership classifications: senior, junior and modified.

It is possible to gain an understanding of the 'health' of these organisations and the potential for them to be sustained into the future as centres of community physical activity. Three of the four sporting associations reported an increase in total membership and so the data are in broad agreement with that reported from the ERASS. ${ }^{11}$ However, of greater interest is the apparent change in the demographic nature of club membership. Three SSAs reported a decrease in numbers of adult members, in contrast to the adult participation levels reported in ERASS ${ }^{11}$ and by the ABS. ${ }^{9,10,13}$ This suggests that an increase in overall adult participation in these sports may mask a decrease in adult club membership. The overall increase in membership has been achieved by some increases in junior membership and by the introduction of the modified sport membership category. The perception of increased club participation is being maintained by sports increasing the scope of their market or market reach.

Two questions become apparent. First, what is the cause of the apparent change in the sporting club membership demographics; and secondly, what are the implications of the change in club membership demographics for those responsible for club sustainability?

There are a number of possible explanations for the reported change in sporting club membership demographics. The expansion of participation in the modified sport group is likely to be the result of a deliberate strategy on behalf of the respective SSAs, State and Commonwealth governments, and organisations focused upon health promotion such as VicHealth, to encourage more young people to participate in organised sport. 6,14 It is also likely to reflect the need for SSAs to increase their market reach thereby creating more sponsorship opportunities, increased membership income and potentially increasing the number of participants in junior and adult ranks in future years.

It is also possible that the increased number of members is related to the phenomenon of 'sport sampling', where young children sample and potentially become members of a range of sports before settling upon a single sport or a smaller number of sports in which to specialise. Sport sampling inflates overall participation estimates, since individual children are represented more than once in counts of registered members of sporting clubs and associations. However, the effect of this phenomenon on apparent trends in participation is less certain. If the extent of sport sampling remains constant over time, any positive trend in participation will be proportionally amplified. However, if the extent of sport sampling changes over time, then estimates of trend in participation will be distorted by these changes.

Junior participation levels were reported to have grown by between $0.5 \%$ and $12.2 \%$ per year. An increase in the number of young people engaged as club members is likely to have a number of positive health outcomes. These include a decreased likelihood of them adopting harmful behaviours during adolescence such as smoking and illegal drug use $\mathrm{e}^{20}$ and an increased likelihood of them participating in some form of regular physical activity as adults. ${ }^{21-23}$ However, it should be noted that the younger children in the junior group are still likely to display 'sampling' behaviour, and therefore it cannot be assumed that the increases apparent in these data necessarily represent an overall increase in sports participation for children.

It is also important to note that the ABS reported that the proportion of the Victorian population represented by children in the 0-14 year age group has been declining. ${ }^{17-19}$ These data represent the continuation of a trend, since children in the $0-14$ age group contributed $20 \%$ of the Victorian population in $200 .{ }^{18}$ Thus the trend towards increasing numbers of young people being recorded as members of these sports within Victoria is occurring at a time when the proportion of children aged 0-14 in the overall Victorian population is falling and the absolute number of children in the population is relatively constant. Notwithstanding the possibility 
that the membership levels of children in the modified and junior classifications represent inflated estimates of both participation rates and trends in participation rates, the focus by governments and SSAs on the provision of program opportunities and the development of coaches appears to be having a positive impact upon involvement of children in sport.

The number of adult members reported by three of the four SSAs was decreasing in both absolute terms and in proportion to the total membership of the sport. In the one sport that did report an increase in senior membership (of $3.4 \%$ per year), the proportion of senior members nevertheless decreased by $2.3 \%$ per year. These decreases in both the number and proportion of adult members occurred during a time when the absolute and proportional contribution of Victorian adults aged 15-30 years, the likely age cohort of most of the adult SSA members, was relatively constant. ${ }^{17-19}$

The reduction in the number of adults participating as members of the sporting associations is likely to be the result of a range of factors including the cost of membership, altered work practices, increased availability of individually focused unstructured activities, the desire and/or need to have more flexible leisure options (including 'pay and play'), transfer to other forms of structured sport, and involvement in a range of non-active leisure pursuits. ${ }^{24}$ Most SSAs did not offer any comment via the web-based survey as to the factors that might be causing the reduction in adult membership. Whatever the reason, there are likely to be a number of consequential impacts arising from this trend. First, it is possible that this trend is indicative of a true decrease in overall participation by adults in physical activity. This proposition is supported by data from the Australian Physical Activity Survey that showed a decrease in the proportion of Australian adults who participate in sufficient physical activity to obtain a health benefit. ${ }^{25}$ Data published from the ERASS survey ${ }^{11}$ appear not to support this argument, since they show that adult physical activity participation is increasing; however the ERASS data include any form of physical activity, irrespective of whether it is sufficient to result in a health benefit.

Given that many of the volunteers who provide the human capital or infrastructure to maintain sporting clubs are drawn from the ranks of current or past adult players, the reduction in adult club membership may have a medium- to long-term negative impact upon the capacity of sporting clubs to support the rising number of junior members with coaches, umpires, club committee members and facilities, and a longer term impact upon the like- lihood of children having parental role models to encourage their participation in sporting clubs. ${ }^{26}$ These data from Victoria showing the proportion of the population with a non-playing sport involvement over an 11-year period was fairly stable. ${ }^{13}$ However, further examination of Australian data for the same period reveals that participation in non-playing roles by individuals in the 15-44 year age group decreased over this period, and the constant overall rate was maintained as a result of an increased proportional involvement of people aged over 45 years of age. Whilst the proportion of the population acting as coaches remained relatively stable from 1993 to $2004,,^{13}$ there were decreases in the proportions involved in umpiring and refereeing or as a committee member. ${ }^{13}$ It is possible that this reduction in sporting club capacity may put major government public health initiatives to combat obesity at risk. 6,7

Finally, the reduction in adult club membership may have a long-term negative impact upon the overall social capital of the communities in which clubs are located. It has been demonstrated that sporting clubs can contribute in a positive manner to the social capital of a community and therefore indirectly to the overall community wellbeing. ${ }^{27,28}$ Therefore, a reduction in adult sporting club membership may have a long-term impact on club sustainability, and hence on community social capital and ultimately community wellbeing.

Membership of a community sporting club offers the potential for individual and community wellbeing and the development or maintenance of social capital to a greater extent than participation in exclusively commercially related settings ('pay and play') or individual physical activity pursuits such as walking. Thorlindsson and Vilhjalmsson ${ }^{29}$ demonstrated that the mental health benefits of sport are more strongly related to participation in club sport than participation in non-club settings.

In conclusion, this study provides an important insight into sport participation and club membership that has not been provided to date. The findings are also important for other countries with similar sport club structure. It has identified decreases in adult club membership which is masked in total membership figures by compensating increases in junior categories and by the extension of reach through modified sport activities. This needs to be addressed to ensure that community sporting clubs can be sustained and fulfil their potential to act as a vehicle for public health initiatives such as those being developed and implemented by international agencies. ${ }^{6,7}$ 


\section{Practical implications}

- There is a need for accurate sports member database systems to inform decision making.

- Specific strategies need to be developed and implemented to engage and maintain adult members of sports clubs.

- State Sporting Associations need to establish strategies to support the transition of young people into adult competition.

\section{Acknowledgements}

This study was funded by VicHealth, as a component of the VicHealth Sport and Active Recreation Schemes Evaluation Project. Staff members from VicHealth are thanked for their overall contribution to the administration of this research and we thank the SSA staff for their contribution to this project.

\section{References}

1. Gray S. Team clubs sports clubs for adults: a model. $A m$ Assoc Behav Soc Sci Online J 2004;7:44-8.

2. Sport England. What Sport England actually does. 2007 [Accessed April 2007].

3. Giles-Corti B, Donovan R. The relative influence of individual, social and physical environment determinants of physical activity. Soc Sci Med 2002;54:1793-818.

4. Steptoe A, Butler N. Sports participation and emotional wellbeing in adolescents. Lancet 1996;347(9018): 1789-92.

5. Stone W, Hughes J. Social Capital: linking family with community. Australian Institute of Family Studies; 2001.

6. Commonwealth of Australia. Backing Australia's sporting ability: a more active Australia. Canberra: Department for Sport and Tourism; 2001.

7. Sport England. Resources for sport/physical activity and health. www.sportengland.org/iyr_north_west-health; 2007 [Accessed April 2007].

8. Australian Bureau of Statistics. Sport volunteers and other volunteers: Some data from the 2002 General Social Survey. Australian Bureau of Statistics: Canberra; 2005.

9. Australian Bureau of Statistics. Participation in sport and physical activities, 1999-2000, Australia. Australian Bureau of Statistics: Canberra [Cat. No. 4177.0. 2000].

10. Australian Bureau of Statistics. Participation in sport and physical activities, 2002, Australia. Australian Bureau of Statistics: Canberra. p. 1-40 [Cat. No. 4177.0. 2003].
11. Standing Committee on Recreation and Sport. Participation in Exercise Recreation and Sport Annual Report 2004. Australian Sports Commission: Canberra; 2005. p. 164.

12. Australian Bureau of Statistics. Involvement in organised sport and physical activity, Australia. Canberra: Australian Bureau Of Statistics; 2002.

13. Australian Bureau of Statistics. Participation in Sports and Physical Recreation, Australia, 2005-2006. Australian Bureau of Statistics: Canberra [Cat No. 4177.0. 2007].

14. VicHealth. Partnerships for Health Scheme (2003-2006) Funding Guidelines. Melbourne: VicHealth; 2003.

15. Council of Europe. Definition of sport; 2007 [cited Accessed April 2007].

17. Australian Bureau of Statistics. Population by Age and Sex, June 2005, Australian States and Territories. Australian Bureau of Statistics: Canberra [Cat No. 3201.0. 2005].

18. Australian Bureau of Statistics. Population by Age and Sex, June 1997 to June 2002. Australian Bureau of Statistics: Canberra [Cat No. 3201.0. 2002].

19. Australian Bureau of Statistics. Population by Age and Sex, June 2004, Australian States and Territories. Australian Bureau of Statistics: Canberra [Cat No. 3201.0. 2004].

20. Pate RR, Trost SG, Levin S, Dowda M. Sports participation and health-related behaviors among US youth. Archiv Pediatr Adolesc Med 2000;154:904-11.

21. Beunen G, Lefevre J, Philippaerts R, Delvaux K, Thomis M, Claessens A, et al. Adolescent correlates of adult physical activity: a 26-year follow-up. Med Sci Sport Exerc 2004;36(11):1930-6.

22. Kraut A, Melamed S, Gofer D, Froom P. Effect of school age sports on leisure time physical activity in adults: the CORDIS Study. Med Sci Sport Exerc 2003;35(12):2038-42.

23. Tammelin T, Nayna S, Rintamaki H, Zitting P. Occupational physical activity is related to physical fitness in young workers. Med Sci Sports Exerc 2002;34(1):15866.

24. Seefeldt V, Malina RM, Clark MA. Factors affecting levels of physical activity in adults. Sports Med 2002;32(2):143-68.

25. Armstrong T, Bauman A, Davies J. Physical activity patterns of Australian adults. In: Results of the 1999 National Physical Activity Survey. Canberra: Australian Institute of Health and Welfare; 2000.

26. Moore LL, Lombardi DA, White MJ, Campbell JL, Oliveria SA, Ellison RC. Influence of parents' physical activity levels on activity levels of young children. $J$ Pediatr 1991;118(2):215-9.

27. Stone W. Measuring social capital: towards a theoretically informed measurement framework for researching social capital in family and community life. Melbourne: Australian Institute of Family Studies; 2001.

28. Townsend M, Moore J, Mahoney M. Playing their part: the role of physical activity and sport in sustaining the health and well being of small rural communities. Rural and remote health 2002; online 109: 7.

29. Thorlindsson T, Vilhjalmsson R, Valgeirsson G. Sport participation and perceived health status: a study of adolescents. Soc Sci Med 1990;31(5):551-6. 